Pesq. Vet. Bras. 35(3):274-280, março 2015

DOI: $10.1590 / \mathrm{S} 0100-736 \mathrm{X} 2015000300011$

\title{
Normal values of $b$-wave responses of full-field electroretinogram in Lhasa Apso dogs with cataracts according to age ${ }^{1}$
}

\author{
Ana C.A. Góes², Tatiane Villar², Denise A. Otsuki³ ${ }^{3}$ Ricardo Lisak², Ricardo A. \\ Pecora $^{2}$ and Angélica M.V. Safatle ${ }^{2 *}$
}

\begin{abstract}
Góes A.C.A., Villar T., Otsuki D.A., Lisak R., Pecora R.A. \& Safatle A.M.V. 2015. Normal values of $b$-wave responses of full-field electroretinogram in Lhasa Apso dogs with cataracts according to age. Pesquisa Veterinária Brasileira 35(3):274-280. Clínica Veterinária Vetmasters, Avenida Pacaembu 1166, São Paulo, SP 01234-000, Brazil. E-mail: asafatle@gmail.com

Lhasa Apso dogs with immature, mature or hypermature cataracts were divided into four groups according to their age (G1: 1 to 3 years old, G2: 4 to 7 years old, G3: 8 to 11 years old, G4: more than 12 years old). All animals were evaluated under the same sedation protocol to allow the performance of the electroretinogram (ERG) exam to determine normal value of $b$-wave response of the full-field ERG according to age. Three ERG responses were recorded: rod, maximal and cone responses. The amplitude values and $b$-wave implicit time of the responses of all groups were compared and analyzed by Kruskal-Wallis test (variance analysis for non-repeated measures), followed by the Dunn post-test (when $\mathrm{p}<0,05)$. A significant decrease was observed in maximal responses' amplitude, when comparing the G4 group with G1 and G2. No statistically relevant differences were observed in the b-wave implicit time values between groups. The ERG values are directly influenced by the animal's age. Older patients presented a decrease in the amplitude of the maximal response. The study determined the normal parameters of ERG b-waves for Lhasa Apso dogs with cataract according to their age group.
\end{abstract}

INDEX TERMS: Electroretinogram, cataract, dogs, Lhasa Apso.

RESUMO.- [Valores de normalidade das respostas da onda-b do eletrorretinograma de campo total (ERG) em cães da raça Lhasa Apso com catarata de acordo com a faixa etária.] Cães da raça Lhasa Apso com catarata imatura, madura e hipermadura foram subdivididos em 4 grupos (G1: 1 a 3 anos, G2: 4 a 7 anos, G3: 8 a 11 anos, G4: acima de 12 anos), submetidos ao mesmo protocolo de sedação para a realização do exame de eletrorretinograma (ERG),com o objetivo de determinar o valor de normalidade da resposta da onda-b do ERG de campo total. Três respostas foram obtidas: resposta de bastonetes, máxima resposta e resposta de cones. Os valores da amplitude pico a pico e do tempo de culminação da onda-b dos grupos foram comparados e ana-

\footnotetext{
${ }^{1}$ Received on October 9, 2014.

Accepted for publication on February 25, 2015.

${ }^{2}$ Clínica Veterinária Vetmasters, Avenida Pacaembu 1166, São Paulo, SP 01234-000, Brazil. *Corresponding author: asafatle@gmail.com

${ }^{3}$ Laboratório de Anestesiologia LIM08, Hospital das Clínicas, Faculdade de Medicina, Universidade de São Paulo, Rua Dr. Ovídio Pires de Campos 225, Cerqueira César, São Paulo, SP 05403-010, Brazil.
}

lisados pelo teste de Kruskal-Wallis (análise de variância por medidas não repetidas), seguido pelo teste de Dunn (quando $\mathrm{p}<0,05$ ). Quando comparado G4 ao G1 e G2, observou-se diminuição significantiva na amplitude da máxima resposta, sugerindo influência da idade nos parâmetros eletroretinográficos. Não foi observada diferença significativa nos valores obtidos do tempo de culminação em nenhuma das respostas dos quatro grupos analisados. Este estudo determinou os parâmetros normais da onda b no ERG dos cães da raça Lhasa Apso com catarata de acordo com a faixa etária.

TERMOS DE INDEXAÇÃO: Eletrorretinograma, catarata, caninos, LhasaApso.

\section{INTRODUCTION}

The full-field electroretinogram (ERG) is a complex recording of electrical potentials, originated from the retinal response to light stimulation (Pereira et al. 2003). It is a very precise electrophysiological test of retinal function evaluation (Komáromy et al. 1998) and has the advantage to be a noninvasive technique (Safatle et al. 2005). 
The main indication for the assessment of ERG in veterinary ophthalmology is as a preoperative examination in dogs with cataracts (Safatle et al. 2010a), which is the most common intraocular disease in dogs (Davidson \& Nelms 1999) and one of the main causes of blindness in this species (Glover \& Constantinescu 1997, Adkins \& Hendrix 2003, Laus 2009).

The cataract is a relatively common affection in Lhasa Apso (LA) dogs. Therefore, the ERG has been frequently performed in these animals. However, normal ERG values are still not established for the breed.

Determination of normal ERG values is of great importance in order to make this exam of real usefulness in clinical practice (Paranhos et al. 2002). Considering that there are variable intrinsic and extrinsic factors that contribute to interfere in the values obtained from ERG recording, it is mostly difficult to establish a normal range. The main intrinsic factors that may interfere in the results are the retinal function, dark/light adaptation, species, age, opaque media and pupillary dilation. The extrinsic factors consist mainly of the duration and intensity of light stimuli, dark/light adaptation period, anesthetic protocol, positioning and electrode type, recording equipment and environmental condition. All these factors are variables among different veterinary clinics, laboratories or hospitals (Ekesten 2007, Lee et al. 2009). Therefore, it is highly recommended that each laboratory establishes its own normal parameters to avoid misinterpretation of results (Mentzer et al., 2006, Noman et al. 2008).

Thereby, as the use of this exam becomes more frequent in the clinical practice of veterinary medicine, notably in dogs of the LA breed and by the absence of related data in the literature, it was conceived to determinate the values of b-wave responses of full-field ERG in Lhasa Apso dogs of different ages and with cataract of stages where lens opacity disturbs the performance of a good fundoscopy (immature, mature and hypermature stages), using the portable device BPM 200 (RetinoGraphics, Inc., Norwalk, CT, USA).

\section{MATERIALS AND METHODS}

A total of 86 electroretinograms were performed in LA dogs with cataracts using the BPM 200 Electroretinographic System (RetinoGraphicsInc, Norwalk, CT, USA), at the Clínica Veterinária Vetmasters, located in São Paulo, Brazil, during the period from $\mathrm{Fe}-$ bruary 2000 to December 2012. Among these 86 dogs included in the study, 36 were females and 50 were males, and their ages varied between one and thirteen years old. Inclusion criteria for this study were Lhasa Apso dogs with cataracts varying between immature, mature and hypermature stages and without any other ocular disorders in at least one eye.

Only one eye of each animal was considered in the statistical analysis. The eye of each animal was chosen based to the absence of other abnormalities, ocular ultrasound results with no alteration, good waveforms and without excessive noise in the results than the other eye.

An actual total of 106 Lhasa Apso dogs were examined during that period, but twenty of these animals were excluded from this study, due to the presence of other ocular associated disorders besides the cataract, as for example glaucoma and uveitis, and as well as those patients whose indication for the ERG exam was other than a preoperative examination for the cataract surgery, as for example the SARDS (Sudden Acquired Retinal Degeneration Syndrome) or PRA (Progressive Retinal Atrophie).

The animals were divided into four groups, according to their age: G1 from one year to three years and eleven months old (14 eyes), G2 from four years to seven years and eleven months old (40 eyes), G3 from eight years to eleven years and eleven months old ( 26 eyes), and G4 from over twelve years old ( 6 eyes).

The exams were performed in a surgery room, where no external light could enter the room, with the animal placed on a surgery table covered by a rubber mat to reduce electrical interference. When necessary, a dim red light was used to place, check or move the electrodes.

The anesthetic protocol was the same to all animals: $0.3 \mathrm{mg} /$ kg xylasine hydrochloride $2 \%$ (Xilazin $2 \%{ }^{\circledR}$, Syntec, Hortolândia, SP, Brasil) and $0.2 \mathrm{mg} / \mathrm{kg}$ butorphanol (Turbogesic $10 \mathrm{mg}{ }^{\circledR}$, Fort Dodge Saúde Animal Ltda, Campinas, SP, Brazil), both via intramuscular. Pupillary dilation was obtained with one drop of topical tropicamide 1\% eye drop (Mydriacyl 1\% ${ }^{\circledR}$, Alcon Laboratórios Ltda, São Paulo, SP, Brazil) applied 30 minutes prior to the exam. Also, the inner face of the earlobes were clipped and cleaned prior to the exam.

Topical anesthesia was performed with proxymetacainechloridate $5 \%$ eye drop (Anestalcon ${ }^{\circledR}$, Alcon Laboratórios Ltda, São Paulo, SP, Brazl) before placement of the ERG-jet contact lens electrodes.

After preparation and sedation of the patients, the animals were taken into a dark room, where dark adaptation was performed for 30 minutes with the aid of an occlusive bandage around

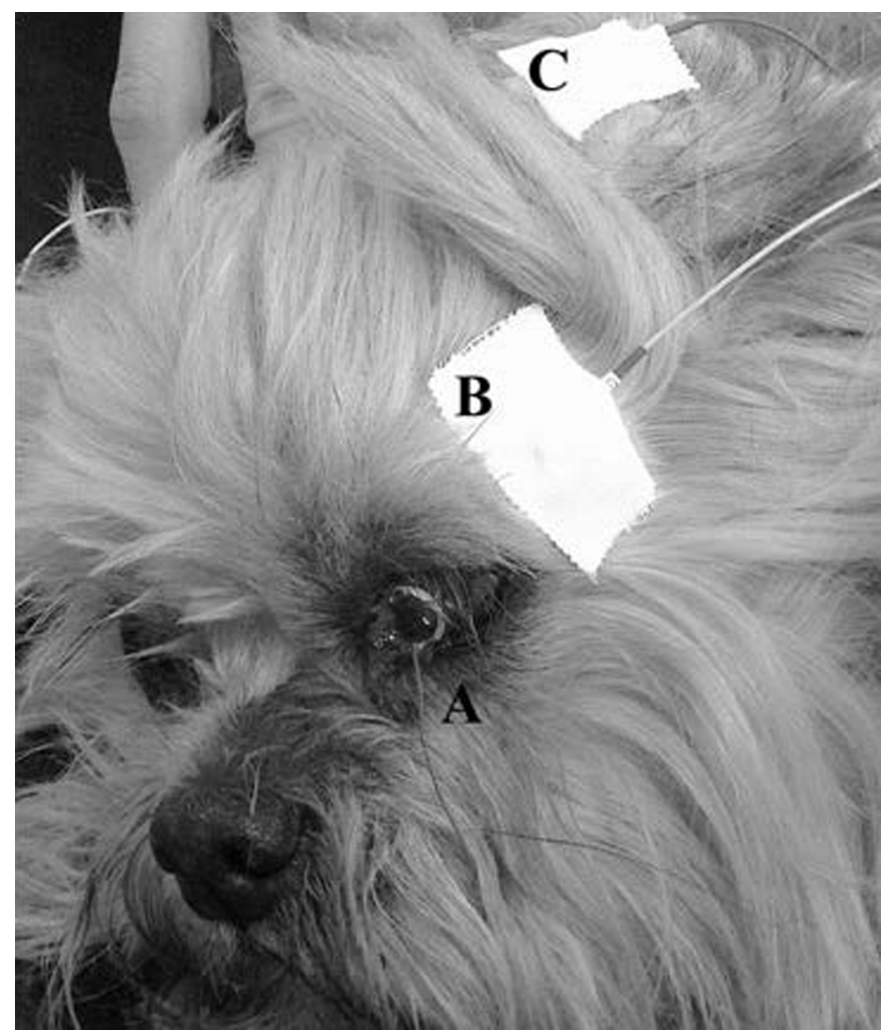

Fig.1. A male Lhasa Apso dog during electroretinography exam, with electrodes properly attached. 1A: ERG-jet contact lens electrode placed upon the cornea; 1B: reference electrode positioned at the temporal canthus and covered with adhesive plaster; 1C: ground electrode placed at internal face of earlobe and covered with adhesive plaster. 
the eyes to ensure full darkness. The bandage was then removed and topical anesthesia applied. The patients were then positioned in lateral recumbency, first the right side and then the left side, to permit the execution of the scotopic phase of the exam without jeopardizing the dark adaptation of the other eye.

The ERG-jet contact lens electrodes were filled with 2\% methylcellulose (Metilcelulose $2 \%{ }^{\circledR}$, Ophthalmos Ind. Farmacêutica, São Paulo, SP, Brazil) prior to its placement, in order to improve electrical contact and protect ocular surface. The reference electrode was filled with electrolytic gel (Ten $20{ }^{\circledR}$ Conductive Paste, Weaver and Company, Aurora, CO, USA) and placed at the temporal canthus of the eye. The ground electrode was also filled with electrolytic gel and fixed at the internal face of the earlobe that were previously clipped and cleaned (Fig.1). With the animal in lateral recumbency, the right eye was the first to be examined.

Dark-adapted rod response was the first to be recorded, using maximal intensity white light $\left(0.01\right.$ cd.s. $\left.\left(\mathrm{m}^{-2}\right)^{-1}\right)$ and a inter-stimuli interval o 2s. Then, mixed dark-adapted rod and cone response, also denominated maximal scotopic response, was recorded using high intensity stimuli $\left(2.5 \mathrm{~cd} . \mathrm{s}^{-1}\left(\mathrm{~m}^{-2}\right)^{-1}\right)$ and a inter-stimuli interval of $10 \mathrm{~s}$.

After the scotopic phase, light adaptation was performed for 10 minutes with external light of 30 cd.s. $\left(\mathrm{m}^{-2}\right)^{-1}$, as a preparation for the photopic phase of the exam. Finally, cone response was obtained using maximum intensity light stimulation $\left(2.5 \mathrm{~cd} . \mathrm{s} .\left(\mathrm{m}^{-2}\right)^{-1}\right)$ with an inter-stimuli of $1 \mathrm{~s}$. In this phase, the left eye was first evaluated then the right, to facilitate recumbence side alternations.

For the three responses, an average of 16 stimulations was performed. At the end of the exam, the b-wave amplitude $(\mu \mathrm{V})$ was measured from the trough of the a-wave to the peak of the b-wave and the b-wave implicit time (ms) from the onset of the stimulus to the peak of the b-wave. Both measurements were obtained in all three responses of each animal. Attenuated or extinct responses were excluded from this study.

It was verified that the variables did not present a normal distribution, when analyzed by the Kolmogorov-Smirnov test. The responses of all different groups were analyzed by the Kruskal-Wallis test (variance analysis for non-repeated measurements), followed by the Dunn post-test (when $\mathrm{p}<0.05$ ) to allow further comparison between groups. Statistical significance was set at $5 \%(\mathrm{p}<0.05)$. The statistical analysis were performed in computer programs (SigmaStat 11.0 and GraphPad Prism 5).

\section{RESULTS}

The measurements of the b-wave amplitude and of the b-wave implicit time of rod response, maximal response and cone response are presented in Table 1, along with average, standard deviation, median, 25 th percentile, 75 th percentile and the minimum and maximal values of each response. The data are subdivided into groups according to the age group of the animals.

A lower amplitude in maximal-responses was observed, when comparing G4 with G1 and G2 (Fig.2). Associating age with rod-responses, we detected a correlation, although not significant, of a progressive lower response with the progression of age. B-wave cone implicit time was delayed with the progression of age and maximal B-wave implicit time remained unaltered regardless of age. No other responses had evidence of any statistical significance.
Table 1. Amplitude $(\mu \mathrm{V})$ and implicit time (ms) of rod, maximal and cone responses, of the four age groups of Lhasa Apso dogs with cataracts

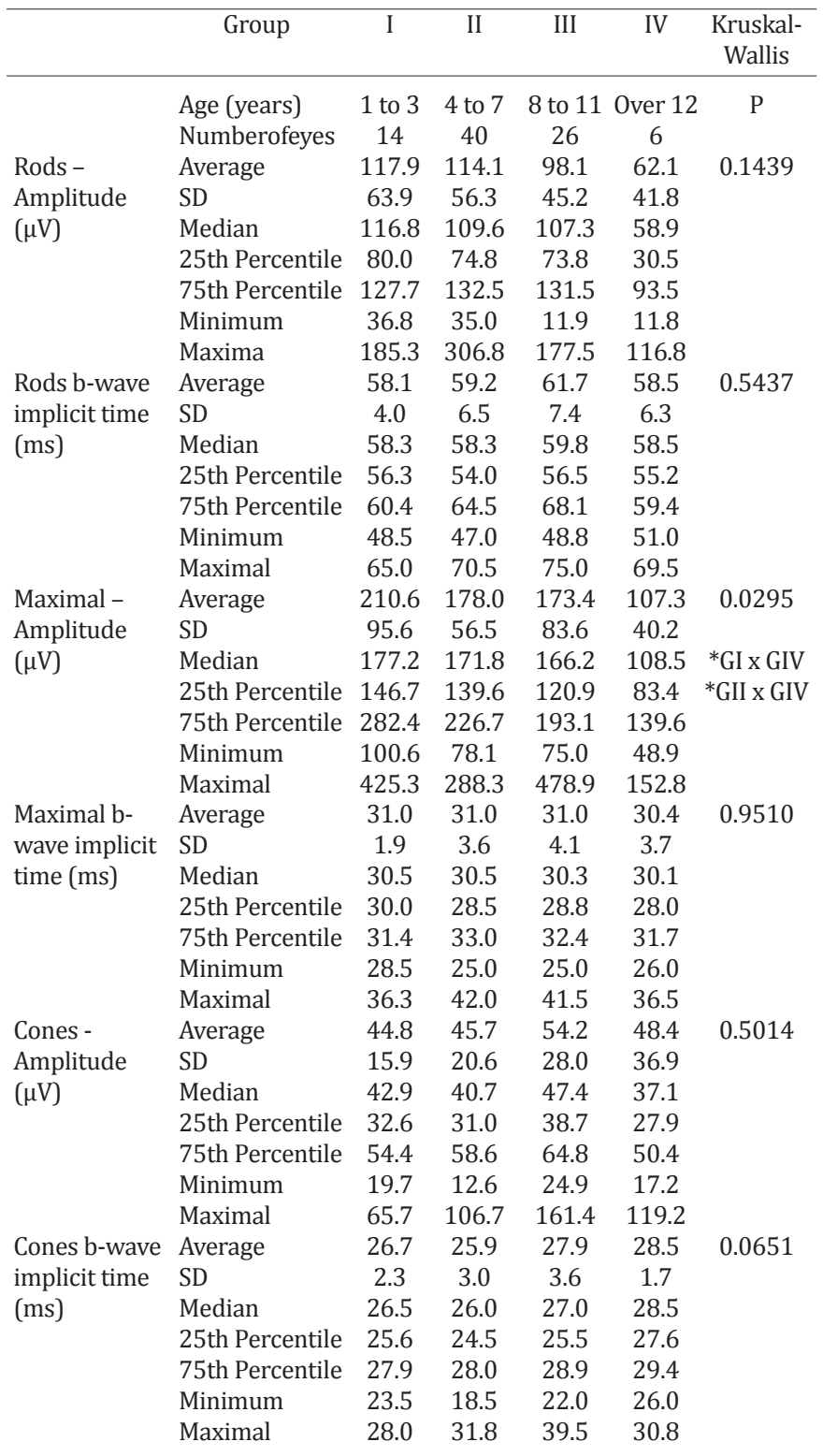

$\overline{\mu \mathrm{V}=\text { microvolts, } \mathrm{ms}}=$ milliseconds, $\mathrm{SD}=$ standard deviation, ${ }^{*} \mathrm{p} \leq 0.05$ (Dunn post-test).

\section{DISCUSSION}

The full-field ERG is the most used electrophysiological test in veterinary ophthalmology, since it is objective (Tzekov \& Arden 1999) and more sensitive than other examination techniques, such as the fundoscopy. Therefore, it allows the diagnosis of retinal alterations on early stages of the disease or, even, when fundoscopy is impaired due to media opacities, as, for example, the cataract (Komáromy et al. 1998).

Retinal degeneration is a much less commonly observed disease in Lhasa Apso dogs in our clinical practice, contrary to what is observed in Poodle or Cocker Spaniel dogs, who are genetically predisposed to cataracts and retinal progressive atrophy (Adkins \& Hendrix 2005). In the meantime, as cataract in this breed is becoming more frequen- 

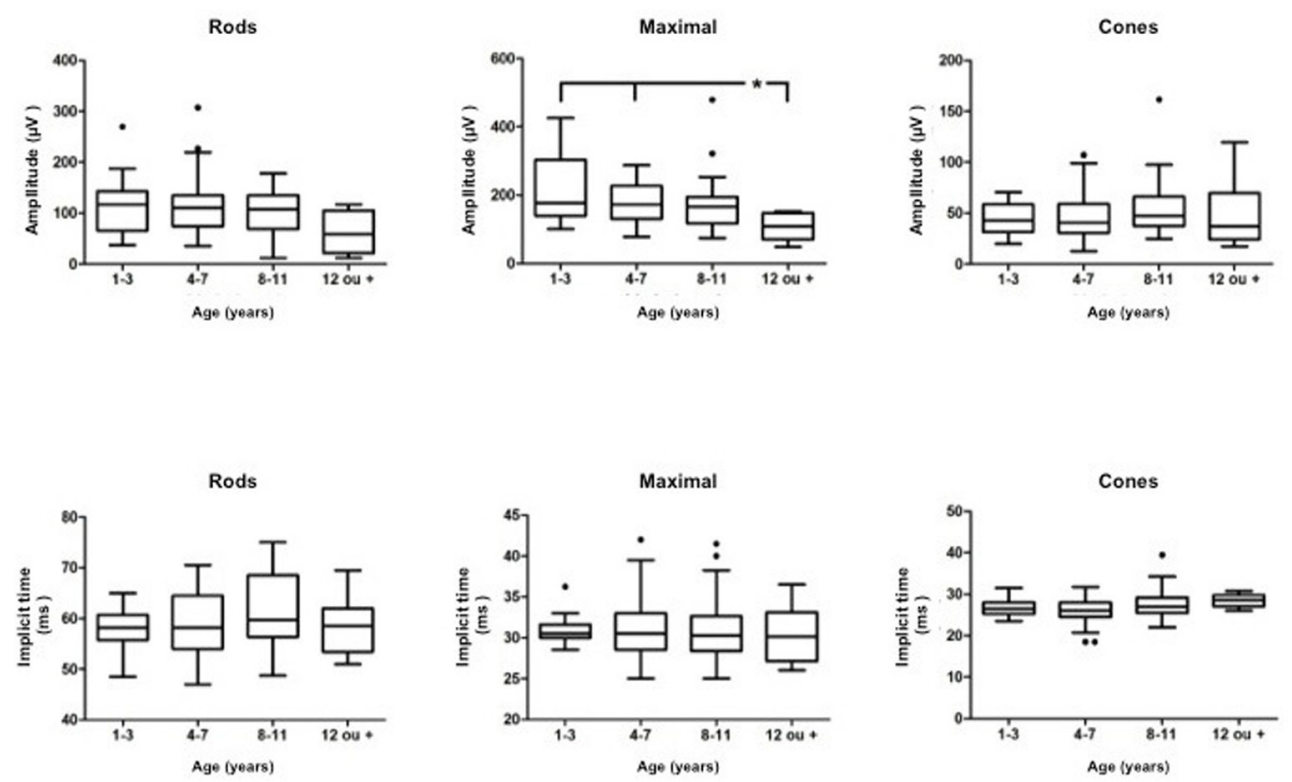

Fig.2. Graphic representation of the b-wave amplitude $(\mu \mathrm{V})$ and implicit time $(\mathrm{ms})$ values of rods, maximal and cones responses obtained of all age groups of Lhasa Apso dogs with cataracts. ${ }^{*} \mathrm{p} \leq 0.05 ; \bullet$ outliers.

tly observed in our daily routine, the ERG is important for testing normal retinal activity, once the cataract consists in a physical impediment to the ophthalmoscopy.

Thereby, ERG is a mandatory exam in those patients, who are candidates for cataract surgery, constituting an important pre-operatory exam in these animals. In a recent study, Chiu et al (2009) evidenced that $27 \%$ of dogs with cataracts, that underwent ERG examination, had a certain degree of retinal dysfunction, and correlated this fact to inherited PRA as the most likely cause, due to a large population percentage of Schnauzers, Poodles, Pomeranians and Cocker Spaniels in the study. Therefore, the importance of a full-field ERG long protocol, which offers a more thorough assessment of retinal responses and function, is to provide the clinician and surgeon with more precise information to decide whether elective surgery should be performed. In addition, the concept of yes-or-no ERG protocol, used as a quick determination for whether retinal function is present or absent before cataract surgery, has been questioned (Ekesten et al. 2012).

Some precautions must be taken in order to perform the ERG, such as the maintenance of a fasting period of food and water prior to the exam, due to the sedation required. Furthermore, the patient's cooperation is also required, since the patients must remain motionless (Narfström 2006), a condition which was successfully achieved by the sedation protocol used in this study, without disturbing or compromising the results.

Recently, a study experimented performing the yes-or-no ERG protocols in dogs under three different consciousness state (awake, sedated and anesthetized) and results demonstrated that the awake animals had higher a- and b-wave amplitudes and shorter a-wave implicit time than those from sedated or anesthetized dogs. Also, the b-wave implicit time was shorter in awake animals than in sedated, but not significantly different from the anesthetized. No significant difference was observed in results between sedated or anesthetized dogs or among consciousness state for high or low frequency noise (Freeman et al. 2013).

ERG exams have been performed in the latest years with the use of xylazine, ketamine and medetomidine as anesthetic agents (Chaudieu 2004, Rosolen et al. 2004). The combination of xylazine and butorphanol in this study, provided a good sedation and allowed adequate recording and low noise interference. No alterations were observed on ERG results due to the sedation protocol, as it may be observed when conducted with barbiturate or inhalation anesthetic agents (Norman 2008, Ekesten et al. 2012).

Satisfactorily pupil dilatation, to allow adequate retinal stimulation, proved to be important for the success of the exam in our study, in agreement to the studies of Birch (1989).

According to Mentzer et al. (2006), ERG results interpretation must consider the species, breed and age of the animal, thus the presence of mean opacities, electrode kind, electroretinogram system used and the sedation protocol. In this study, the animals were divided into groups according to their age, the electrodes and electroretinogram system used were of the same type and sedation protocol performed was identical to all animals.

The assessment of a unilateral or bilateral ERG depends on the species, the equipment used and the purpose of the exam (Narfström 2006). In this study, each eye was individually examined with the animal on lateral recumbence to avoid the light stimulation to reach the other eye.

In comparison with another similar study from the same authors on Poodle dogs, the Lhasa Apso dogs presented expressively higher mean values of maximal amplitude than the other measured responses. As an example, the mean values of amplitude in Poodle dogs with cataract divided into groups according to their age exactly as in this present study (from one to 3 years, 4 to 7 years, 8 to 11 years, and 

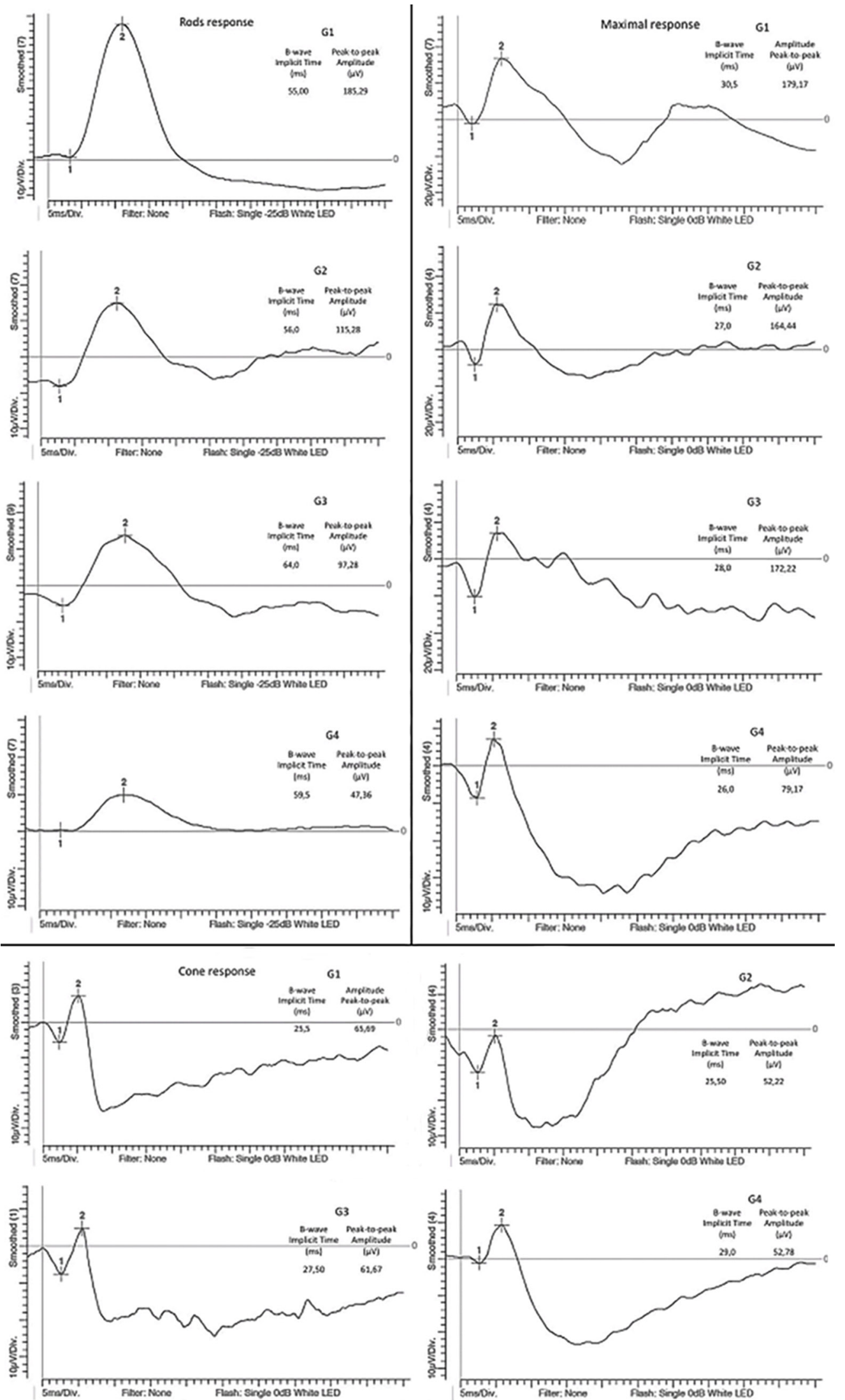

Fig.3.Electroretinographic traces with b-wave implicit time and peak-to-peak amplitude values of rods, maximal and cones responses of Lhasa Apso dogs with cataracts, subdivided into four groups according to age: G1 from one to 3 years and 11 months old, G2 from 4 years to 7 years and 11 months old, G3 from 8 years to 11 years and 11 months old, and G4 from over 12 years old. The traces were chosen from a sample that best characterized the group. Note the progressive decrease of amplitude value through G1 to G4. 
over 12 years old), were, respectively, of $152.3 \mu \mathrm{V}, 145.42 \mu \mathrm{V}$, $128.16 \mu \mathrm{V}$ and $105.7 \mu \mathrm{V}$ (Safatle et al. 2010b). Meanwhile, the mean values of maximal amplitude in the Lhasa Apso dogs, were of $210.6 \mu \mathrm{V}, 178.0 \mu \mathrm{V}, 173.4 \mu \mathrm{V}$ and $107.3 \mu \mathrm{V}$, respectively, using the same electroretinogram system, at the same location, with the same veterinarians and sedation protocol. Therefore, it may be inferred that the response's values of the Lhasa Apso dogs are substantially higher, in particular of the youngest animals. The implicit time of the responses, however, remain similar between breeds.

In the same study of Safatle et al. (2010b), a decrease in the amplitude values was observed in all responses, when comparing dogs from G1 (with ages up to 3 years old) with the other groups in the study, meaning that the amplitude of the responses decreases with the animal's aging (Fig.3). Moreover, the implicit time of rod response observed in this group was delayed when compared to the rest. Such findings contrast with those of this present study, in which a statistically significant difference was verified only in the maximal response when comparing groups G1 with G4, and G2 with G4. Furthermore, no statistically relevant alterations were observed in the b-wave implicit time of this study.

Nevertheless, if comparing the dogs in this study with Cocker Spaniel dogs in another study from Safatle et al. (2010a), the same situation is verified: higher mean values of amplitude in Lhasa Apso dogs.

In a study to standardize the ERG values in Shih Tzu dogs, Lee et al. (2009) also demonstrated lower values of amplitude, when confronted with the same data of the Lhasa Apso dogs. However, the legitimacy of such comparison is questionable, not only due to differences in the sedation protocol, in the adaptation time and in the response pattern recorded, but also due to the electroretinograph (Handheld Multispecies ERG) used. Moreover, the sample was composed by young dogs without any ophthalmic disorder, what also differs from our study, which included only dogs with cataracts. According to Maehara et al. (2007), the amplitude of all responses increases substantially after the cataract removal, in comparison with the amplitude prior to the surgery.

In this study, a distinguished heterogeneity of the sample was observed, mainly regarding to the group division by age. It is, consequently, assumed that cataract in this breed is a disorder that affects mainly adults, what would explain the larger number of animals grouped in G2 and G3. Other hypothesis could explain the lowest amount of animals grouped in G4 besides the lower frequency of cataract in older animals of this breed, as, for example, the owner's reluctance in submitting his animal to an exam that requires sedation.

\section{CONCLUSIONS}

The electroretinogram response is directly influenced by the animal's age;

Older patients present a decrease in the amplitude of maximal response;

No detectable alterations were observed in the implicit time of all different age groups;
This study also determined the normal parameters of Lhasa Apso dogs with cataracts, demonstrating the lowest and maximal values for each response in all different age groups, and also allows to infer that Lhasa Apso dogs present considerably higher response values than other breeds whose data have already been determined;

More studies are necessary in order to standardize the full-field ERG results in the Lhasa Apso breed, considering the limitations of this study, such as the low amount of patients over 12 years old and of the sample as a whole;

Furthermore, it is suggested that other subsequent studies may clarify the possible existence of a relation between the animal's pelage and the electroretinogram responses, as an example of what occurs in albino animals;

Regardless of the referred limitations, this study fills part of a lacuna in the knowledge of electrophysiology in Lhasa Apso dogs, whose specific data has not been established until the present time.

\section{REFERENCES}

Adkins E.A. \& Hendrix D.V.H. 2003. Cataract evaluation and treatment in dogs. Compendium on Cont. Educ. Pract. Vet. 25(11):812-824.

Adkins E.A. \& Hendrix D.V.H. 2005. Outcomes of dogs presented for cataract evaluation: a retrospective study. J. Am. Anim. Hosp. Assoc. 41:235240.

Birch D.G. 1989. Clinical electroretinography. Ophthalmol. Clin. North Am. 2(3):469-497.

Chaudieu G. \& Molon-Noblot S. 2004. Early retinopathy in the Bernese Mountain Dog in France: preliminary observations. Vet. Ophthalmol. $7(3): 175-184$

Chiu En-I., Fei A.C.Y. \& Lin C.T. 2009. Characteristics of electroretinograms in canine eyes with cataracts. Taiwan Vet. J. 35(4):225-232.

Davidson M.G. \& Nelms S.R. 1999. Disease of the lens and cataract formation, p.797-825. In: Gelatt K.N. (Ed.), Veterinary Ophthalmology. 3rd ed. Williams and Wilkins Lippincot, Philadelphia.

Ekesten B. 2007. Electrodiagnostic evaluation of vision, p.520-535. In: Gelatt K.N. (Ed.), Veterinary Ophthalmology. 4th ed. Blackwell Publishing Ltd, Oxford.

Ekesten B., Komáromy A.M., Ofri R., Petersen-Jones S.M. \& Narfström K. 2012. Guidelines for clinical electroretinography in the dog: 2012 update. Doc. Ophthalmol. 127:79-87.

Freeman K.S., Good K.L., Kass P.H., Park S.A., Nestorowicz N. \& Ofri R. 2013. Effects of chemical restraint on electroretinograms recorded sequentially in awake, sedated, and anesthetized dogs. Am. J. Vet. Res. 74(7): 1036-1042.

Glover T.D. \& Constantinescu G.M. 1997. Surgery for cataracts. Vet. Clin. North Am., Small Anim. Pract. 27(5):1143-1173.

Komáromy A.M., Smith P.J. \& Brooks D.E. 1998. Electroretinography in dogs and cats. Part I. Retinal morphology and physiology. Compend. Contin. Educ. Pract. Vet. 20:343-354.

Laus J.L. 2009. Oftalmologia clínica e cirúrgica em cães e gatos. Roca, São Paulo. 230p.

Lee J.S., Kim K.H., Jang H., Lee B., Kim J.Y. \& Jeong S.W. 2009. The normal electroretinogram in adult healthy Shih Tzu dogs using the HMsERG. J. Vet. Sci. 10(3):233-238.

Maehara S., Itoh N., Wakaiki S., Yamasaki A., Tsuzuki K. \& Izumisawa Y. 2007. The effects of cataratact stage, lens-induced uveítes and cataratact removal on ERG in dogs with cataract. Vet. Ophthalmol. 10(5):308312.

Mentzer A.E., Eifler D.M., Montiani-Ferreira F., Tuntivanich N., Forcier J.K. \& Petersen-Jones S.M. 2006. Influence of recording electrode type and reference electrode position the canine electroretinogram. Doc. 
Ophthalmol. 111(2):95-106.

Narfström K. 2006. Electroretinographic testing in large animals, p.923933. In: Heckenlively J.R. \& Arden G.B. (Eds), Principles and Practice of Clinical Electrophysiology of Vision. Mit Press, Cambridge.

Norman J., Narfström K. \& Barrett P.M. 2008. The effects of medetomidine hydrochloride on the electroretinogram of normal dogs. Vet. Ophthalmol. 11(5):299-305.

Paranhos F.R.L., Paranhos J.R.A. \& Nehemy M.B. 2002. Eletrorretinograma: considerações a respeito dos limites de normalidade e comparação entre valores normais de dois diferentes laboratórios. Arq. Bras. Oftalmol. 65:213-216.

Pereira J.M., Mendieta L., Sacai P.Y., Salomão S.R. \& Berezovsky A. 2003. Estudo normativo do eletrorretinograma de campo total em adultos jovens. Arq. Bras. Oftalmol. 66:137-144.

Rosolen S.G., Rigaudiere F., LeGargasson J.F., Chalier C., Rufiange M., Racine
J., Joly S. \& Lachapelle P. 2004. Comparing the photopic ERG i-wavein diferente species. Vet. Ophthalmol. 3:189-192.

Safatle A.M.V., Hvenegaard A.P., Gomes D., Leandro D.C., Otsuki D.A. \& Lisak R. 2010a. Importância do eletrorretinograma de campo total (fullfield ERG) em cães da raça Cocker Spaniel Inglês portadores de catarata. Pesq. Vet. Bras. 11(2):149-154.

Safatle A.M.V., Lisak R., Otsuki D.A. \& Gomes D. 2010b. Determinação dos valores normais do eletrorretinograma de campo total em cães da raça Poodle portadores de catarata de acordo com a faixa etária. Ciência Rural 40(3):587-593.

Safatle A.M.V., Salomão S.R., Berezovsky A., Sakai P.Y., Fantoni D.T., Yasbek K.V. \& Barros P.S.M. 2005. Retinal degeneration in a Pit Bull dog: electroretinographic findings. Arch. Vet. Sci. 10(2):119-124.

Tzekov R. \& Arden G.B. 1999. The electroretinogram in diabetic retinopathy. Surv. Ophthalmol. 44(1):53-60. 